\title{
The Reference of German Foreign Trade Development to Sino-US Trade Friction
}

\author{
Feng $\mathrm{Ru}$ \\ Shaanxi Normal University International Business School, Xi'an, Shaanxi, China \\ florafeng1993@163.com \\ *Feng $\mathrm{Ru}$
}

Keywords: Germany; trade friction; trade promotion system; FTA.

\begin{abstract}
In the last century, the trade friction between the United States and Japan lasted for 30 years. Germany, which is also in the stage of rapid economic development, is more fortunate than Japan. The dispersion effect, the reciprocal effect and regional effect of German foreign trade make Germany avoid trade friction. At the same time, Germany's foreign trade promotion system and domestic economic policies provide a reference for China to deal with Sino-US trade frictions.
\end{abstract}

\section{德国对外贸易发展对中美贸易摩擦的启示}

\author{
冯茹 \\ 陕西师范大学国际商学院, 西安, 陕西, 中国 \\ florafeng1993@163.com \\ 冯茹
}

关键词：德国; 贸易摩擦; 贸易促进体系; FTA

摘要：上世纪美日之间贸易摩擦持续30年之久, 同样处于经济高速发展阶段的德国却比日本 幸运的多, 德国对外贸易的分散效应, 对等效应和区域效应使得德国避开贸易摩擦。同时德 国的对外贸易促进体系和国内经济政策为我国应对中美贸易摩擦提供借鉴。

\section{1. 引言}

二战结束后，美国确立了资本主义世界霸主地位，在苏联解体后成为世界上唯一的超级 大国。美国利用其在国际上的超然地位, 面对与日本之间贸易的巨额顺差, 于 20 世纪 60 年 代发起对日本的贸易战。双方从贸易领域到金融领域再到制度领域的摩擦持续 30 年, 在美国 强大的贸易保护主义压力下, 尽管日本倍觉不公, 也曾积极的利用各种资源到美国国会中游 说, 但最终都一一做出了让步。让步妥协的结果是, 从 1990 年开始, 日本经济进入了“平成 萧条”，直到今天，也没有出现大的起色。而美国却在 1993 年以后，开始引领全球进入到以 计算机信息技术、能源技术、生物技术等为标志的知识经济时代, 并经历了二战以来的最长 经济增长周期, 美国经济再度崛起。

\section{2. 德国对外贸易效应}

相较而言，同样是处于经济迅速发展阶段的德国就要幸运太多。20 世纪 50 年代以后, 德国的战后重建迅速且成效显著，创造了举世闻名的“德国奇迹”，其制造业水平全球瞩目。 
从 1951 年开始, 德国的外贸顺差就一直以强大的势头逐年增加, 进入 80 年代中期以后, 德 国的出口额更是连续 6 年雄踞各国之上, 而成为世界第二号出口大国。但是面对德国强大的 在经济增长势头, 美国却安然若素。这是因为较之日本, 德国的对外贸易发展具备分散效应, 对等效应和区域效应。

首先是分散效应, 德国对外贸易无论是从出口产品结构还是从出口地区结构都具有分散 的特点, 而这种分散使得德国能避免形形色色的保护主义的冲击, 也减少了贸易摩擦。从出 口产品结构分析，尽管德国的出口长期以来一直以资本货物为主，但德国的出口贸易从没有 依靠某几类商品的出口。在德国的出口总额中从没有一种商品（包括汽车）的出口额能在其 中占 $25 \%$ 以上的份额。相比之下, 日本的出口商品中汽车是一项主要商品, 大量汽车行销欧 美市场, 冲击了欧美的汽车制造业, 导致美国和欧共体数项限制日本小汽车进口的条例, 从而 也引起了美国、欧共体与日本的贸易摩擦。从出口地区结构分析, 德国的出口市场高度分散。 日本在每年近 300 亿美元的出口中几乎有 $50 \%$ 的份额是输给其贸易最大主顾美国的。可是德 国, 除了极为个别公司有较大比例的商品销往美国外, 大多数公司在美国市场的销售额都没 有超过其公司出口总额的 $1 / 10$, 德国除了与美贸易, 还主要与欧共体和欧洲自由贸易联盟进 行贸易。这两大区域内贸易环境极为优越, 于是德国便将其出口总额的 $50 \%$ 以上输入这两个 区域。

其次是对等效应。德国不仅是世界第二大出口国，同时也是世界第二大进口国。这种对 等性大大减少贸易摩擦的可能性, 故而也成为德国对外贸易的潜在优势。德国对外贸易的对 等性表现在进出口地区的对等性及进出口商品结构的对等性, 这两个对等性构成的对等效应 具有极为深刻的作用。反观日本, 将工业制成品销往美国, 产生巨额顺差, 又从发展中国家 进口大量石油等能源, 产生逆差, 国家间贸易的不均衡使得日本面临贸易摩擦的可能性上升。

最后是区域效应。德国对外贸易还具有的一个特点就是其集中在欧共体内部。这种利用 加入欧共体而促使其区内贸易发展是很明智的选择，它可以在欧共体统一贸易条例下与欧共 体其它国家进行不受限制或较少限制的贸易往来。从最早的关税同盟到最近的统一大市场, 对德国的区内贸易都有着极为有利的影响。最初的关税同盟的建立, 有利于德国扩大对其它 成员国的贸易和削弱美国在西欧市场的地位，从而使德国收到一箭双雕的好处。随着欧共体 内统一市场的建成, 德国的区域内贸易得到更为迅速的增长, 欧共体各国在德国的出口和进 口份额中都已超过 $50 \%$, 而成为德国对外贸易最为集中的地区。但这种贸易的增长却不会带 来贸易摩擦, 这既源于德国巧妙的运用了欧共体成员国的身份, 有源于其进口和出口的对等 性。日本没有强有力的区域性经济集团的支持, 其庞大的出口必然引起广泛、深刻的贸易摩 擦。

\section{3. 德国对外贸易发展影响因素}

\section{1 贸易促进体系}

近年来，我国企业在与美国进行贸易时，也面临了许多的贸易救济调查，尤其是特朗普 上台后, 中美两国间的贸易战正式打响。为有效的规避贸易摩擦, 德国的对外贸易促进体系 值得我们学习。

德国联邦经济部支持德国驻外使馆商务代表处的工作，促进在世界范围内建立一个能为 德国企业提供广泛服务的海外商会网, 由此形成外贸促进三大支柱机构:（1)德国驻外使馆商 务代表处。它负责了解驻在国经济贸易情况, 为有意与驻在国开展经贸业务的德国企业提供 信息咨询服务; (2)海外商会。德国工商大会在海外设立海外商会, 为德国企业从事国外业务 提供有力的支持。其服务包括：产品咨询、市场和经济分析、商务咨询、项目咨询和跟踪， 法律和关税咨询等; (3)外贸信息局。主要为企业进入海外市场提供关于地址、经济数据、实 际操作建议和市场分析等信息。与此同时, 发行关于到国外设立代表处和各国经济状况等的 
出版物, 以此向国内企业提供对外贸易的机会。全面而有效的信息使德国企业在海外市场上 想要主动权，有效的规避了贸易摩擦发生的可能。

德国工业企业中绝大多数是中小企业。它们规模虽小，却具有专业化程度高、创新能力 强、经营管理灵活等优势, 是国际经济最有特色和最具活力的部分。近年来, 德国实施了一 系列促进中小企业发展的政策, 有效地推动了中小型企业的迅速发展, 从而提升了德国对外 贸易的竞争力。这些措施包括: 设立专门的政府机构、完备的中介机构, 为中小企业发展提 供全方位的服务; 健全法律制度, 保证促进中小企业发展的政策措施的有效实施; 提供全面 的资金援助, 改善中小企业生存发展的资本环境; 创建先进的技术支持体系, 帮助中小企业 实现科技进步和科研成果的迅速转化。德国企业尤其是为数众多的中小企业在国家贸易促进 体系的推动下, 纷纷走上了国际贸易的路途, 它们凭借强大的政策支持, 以坚实的企业实力 为基础, 以优质的商品和服务为利器, 打开了国际市场的大门, 逐渐在国际贸易市场上占据 主要位置。美国因为国有企业一直质疑我国的市场经济地位, 鼓励和引导中小企业的发展可 以增加竞争活力，同时规避“双反”调查。

\section{2 国内经济政策的影响}

德国对内实行开放和自由的经济政策和贸易政策，而对外采取相应的更加灵活的政策措 施, 如对外积极参加区域性经济合作等, 以此来巩固和加强其在世界经济和国际贸易中的地 位和作用。德国这种开放的、公平的、竞争的国内经济环境为德国企业的茁壮成长创造了一 片沃土。开放的经济有利于企业利用国内、国外两种资源和两个市场, 有利于企业引进和吸 收先进的技术，提高生产效率和商品质量。

\section{4. 德国对外贸易发展对我国的启示}

\section{1 建立新型的对外贸易促进体系}

构建我国新型的贸易促进体系，可以从以下几个方面着手：第一，明确政府部门、中介 机构在贸易促进体系中的职能定位和分工。各级政府应依法行政, 减少对经济的行政干预, 加快构建新型贸易促进体系，促进政府职能以管理为主向以服务为主转变，提高贸易促进的 效率和水平，扶持和促进中小企业开展对外贸易。同时切实提高商业协会等中介机构的服务 能力和服务质量, 提升对出口企业的服务水平; 第二, 完善贸易促进的外部环境。建立完备 的公共信息服务体系, 为企业开拓国际市场, 从事国际贸易活动等提供有效信息和行动指导。 同时加强海关、税务、外汇管理、银行和保险等部门的协调, 提高贸易的便利化程度, 减少 企业成本，提升国际市场竞争力；第三，加强财政对贸易发展的支持力度，提高财政性支持 政策的使用效率。财政部应加大对科技兴贸专项资金和境外投资贸易工作机构运行专项资金 等的投入, 从而提高出口产品质量和境外增长, 改善出口商品结构, 方便企业国际融资, 提 高出口竞争力以及带动劳动力就业等方面的积极作用。

\section{2 加强区域经济合作, 实施FTA战略}

现今, 在由 WTO 主导的多边谈判日益艰难的形势下, 加强区域经济合作, 实施 FTA 战 略已成为中国发展对外贸易的一种必然选择。在实施 FTA 战略的过程中, 应该注重以下几点: 第一，在实现区域内部贸易自由化的同时，逐渐降低对区域外贸易对象的保护水平。按照维 纳的关税同盟理论, 成员国对外开放度的提高, 将会降低贸易转移效应。随着对外开放程度 的不断提高, 我国不仅能获得区域内成员国对本国产品的更大需求, 而且还可以增加对区域 外国家的出口, 从而整体福利水平将得到提高; 第二, 将生产一体化和市场一体化相互结合, 作为我国参与自由贸易区的战略选择由于中国与东盟成员国的经济发展水平不高, 对区域内 市场依赖度较低, 因而通过部门间分工或部门内分工建立生产一体化, 有利于发挥各成员国 的比较优势, 形成紧密的生产链, 实现专业化分工, 从而降低生产成本, 提高整体竞争力。 
而建立区域内市场一体化, 有利于实现区域内资源的优化配置, 为实现专业化分工奠定基础; 第三, 加强区域经济组织运行机制的制度化建设, 以便实现区域经济组织的目标, 发挥区域 经济的积极影响。

\section{References}

[1] Yu Kunpeng. Trade friction and the strategy of the United States to delay China's development [D]. Jinan University, 2010.

[2] Ding Ping, Xu Song. The Development of German Foreign Trade and Its Enlightenment to China [J]. Economic Frontiers, 2007 (06): 27-32.

[3] Zhou Tianqi. Why is Germany less trade friction [J]. International Economic and Trade Exploration, 1993 (06): 68-70.

[4] Xin Yue. Briefly describe the road of foreign trade in Germany [J]. Business culture (first half of the month), 2014 (07): 67-73.

[5] Liu Yan. German foreign trade development analysis and reference [D].Guangxi University,2012.

[6] Jiang Heping. Germany's measures to enhance the competitiveness of foreign trade and its reference [J]. Economic Guide, 2010 (11): 10-11. 